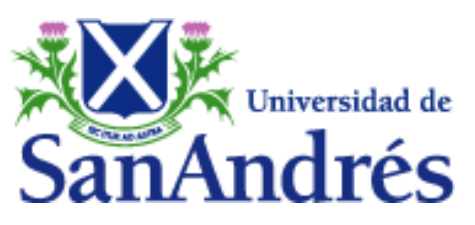

"On Favoritism in Auctions with Entry"

Por Leandro Arozamena (Universidad Torcuato Di Tella \& CONICET) y Federico

Weinschelbaum (Universidad de San Andrés).

D.T.: $\mathrm{N}^{\circ} 103$

Mayo, 2010

Vito Dumas 284, B1644BID, Victoria, San Fernando, Buenos Aires, Argentina

Teléfono 4725-7053, Fax 4725-7010

Email,economia@udesa.edu.ar 


\title{
On favoritism in auctions with entry
}

\author{
Leandro Arozamena ${ }^{2}$ \\ Universidad Torcuato Di Tella and CONICET \\ Federico Weinschelbaum ${ }^{3}$ \\ Universidad de San Andrés
}

February 2010

\begin{abstract}
We examine the problem of endogenous entry in a single-unit auction when the seller's welfare depends positively on the utility of a subset of potential bidders. We show that, unless the seller values those bidders' welfare more than her own "private" utility, a nondiscriminatory auction is optimal.
\end{abstract}

Keywords: auctions, favoritism, free entry, endogenous number of bidders.

JEL classification: C72, D44.

\footnotetext{
${ }^{1}$ We acknowledge financial support from FONCyT, PICT 2255.

${ }^{2}$ Corresponding Author. Address: Saenz Valiente 1010, C1428BIJ Buenos Aires, Argentina. E-mail: larozamena@utdt.edu. Phone: 54-11-5169-7300. Fax: 54-11-5169-7348.

${ }^{3}$ Address: Vito Dumas 284, B1644BID Victoria, Buenos Aires, Argentina. E-mail: fweinsch@udesa.edu.ar. Phone: 54-11-4725-7041. Fax: 54-11-4725-7010.
} 


\section{Introduction}

The most important results in auction theory hold under the assumption of a fixed number of bidders. However, as Klemperer (2004) claims, one of the key issues regarding auction design is how to encourage entry. For instance, Engelbrecht-Wiggans (1987) suggests that New York consolidated as the main port of the US East Coast (over Philadelphia and Boston) after passing legislation (with the express intention of attracting bidders) that required that all goods offered at auction at the New York port should be sold without reservation price to the highest bidder. Another issue that arises quite frequently when auctions are employed, especially in procurement, is whether some of the bidders should be given preferential treatment, e.g. in public procurement when domestic firms have some form of advantage in the bidding process over their foreign rivals. One reason -although not the only possible one- for awarding such a preference is that favored bidders' welfare positively influences the seller's welfare. In our previous example, it may be the case that domestic firms generate more tax revenue than their foreign rivals. Alternatively, the seller and some of the bidders may be firms in the same conglomerate.

Some papers, which we briefly discuss below, study auctions with endogenous entry, but in all of them the seller's utility is not affected by the utility of any of the bidders. Another branch of the literature, which we also discuss below, analyzes auctions where the seller's welfare depends on the utility of some of the bidders, but all of them study the case of a fixed number of bidders Here, we examine the problem of endogenous entry when the seller's welfare depends on the utility of a subset of potential bidders. To the best of our knowledge this note is the first to deal with this problem.

The literature of endogenous entry in auctions can be divided into two groups. First, there are models in which the entry decision is made after each bidder knows her valuation. This set of papers starts with Samuelson (1985) and includes Stegeman (1996), Menezes and Monteiro (2000), Celik and Yilankaya (2009) and Li and Zheng (2009), among others. Alternatively, there are models where the decision is made before the valuation is realized, which is the assumption we adopt. These models start with McAfee and McMillan (1987) and Engelbrecht-Wiggans (1987) and include Engelbrecht-Wiggans (1993); Levin and Smith (1994) and Ye (2004).

As for the issue of favoritism in auctions, Laffont and Tirole (1991) and Vagstad (1995) study the case of multidimensional auctions, where favoritism may appear when the auctioneer assesses product quality. McAfee and McMillan (1989), Branco (1994) and Naegelen and Mougeot (1998) examine single-dimensional auctions, where price-preferences may be used. The basic 
result is that the optimal allocation rule follows from comparing the maximum valuation of the preferred bidders with the maximum "virtual" valuation of the non preferred bidders. A usual way to discriminate, known as right of first refusal, is giving one of the preferred bidders the right to match the highest bid that any of her rivals may submit. This right has been studied in Walker (1999), Burguet and Perry (2009), Bikhchandani et al. (2005), Arozamena and Weinschelbaum (2006), Choi (2009) and Lee (2008).

In what follows, we allow for the possibility that the seller attaches a positive weight to some bidders' utility when computing her own welfare. However, once we endogenize entry, we show that, unless that positive weight is larger than one (i.e. unless the seller values those bidder's welfare more than her own "private" utility), there is an optimal auction design which is nondiscriminatory. The intuition is simple: whenever the seller is able to appropriate the whole surplus in an efficient auction, the joint surplus of the seller and the preferred buyers cannot be improved, and it will certainly decrease whenever preferences introduce some inefficiencies in the auction. In our setup with an endogenous number of bidders, there are nondiscriminatory auctions, which are efficient, that allow the seller to appropriate the whole surplus. There could be some way to discriminate without reducing the seller's welfare, but it is not possible to increase it. As a corollary, we show that awarding a right of first refusal to a preferred bidder, generally reduces welfare.

It should be noted that the justification for favoritism that we examine, which derives from the fact that the seller values some of the bidders' utilities, is not the only possible one. With a fixed number of bidders, favoring weak bidders raises revenue, as shown by optimal auction theory. With endogenous entry, favoring weak bidders (which might otherwise not enter) may also be optimal for the seller. Those arguments require asymmetry among bidders, while our model is (but for the unequal consideration of bidders' utilities by the seller) symmetric. In sticking to symmetry, we concentrate on the reason for favoritism that we intend to question.

In the following section we present the model and the basic results.

\section{The model}

We start with the setup in McAfee and McMillan (1987). Specifically, the owner of a single, indivisible object is selling it through an auction. ${ }^{4}$ For simplicity, we assume the seller attaches no value to the object. There are $N$ potential bidders, any of whom can enter the auction

\footnotetext{
${ }^{4}$ All our results are valid as well in the case of procurement auctions.
} 
upon paying a fixed cost $k \geq 0$. After paying her entry cost, bidder $i$ learns her valuation for the object, $v_{i}$, which is distributed according to a c.d.f. $F$ with support on the interval $[\underline{v}, \bar{v}]$ and a density $f$ that is positive and bounded on the whole support. Bidders' valuations are independent. We assume that $N$ is large enough so that if all potential bidders entered they could not recover the entry cost.

The seller's utility depends on the surplus of one of the bidders, the "preferred" bidder. We assume that there is only one preferred bidder, although our arguments would generalize to the case of any favored subset of $\{1, \ldots, N\}$. We want to characterize a selling mechanism that maximizes the sum of the expected utilities of the seller and the preferred bidder -we assume that the latter is bidder $1 .^{5}$ Our problem is a modification of the standard optimal auction problem with independent private values. ${ }^{6}$ The seller and all bidders are risk neutral.

Let $B$ be the set of bidders that enter the auction. The timing is as follows. First, the seller announces the auctioning mechanism. In principle, she could condition that mechanism on the subset of entering bidders, so she has to announce functions $H_{i}^{B}\left(\left(v_{i}\right)_{i \in B}\right), P_{i}^{B}\left(\left(v_{i}\right)_{i \in B}\right), B \in$ $2^{\{1, \ldots, N\} 7} . H_{i}^{B}\left(\left(v_{i}\right)_{i \in B}\right)\left(P_{i}^{B}\left(\left(v_{i}\right)_{i \in B}\right)\right)$ is the probability that bidder $i$ gets the object (respectively, the price bidder $i$ has to pay to the seller) if $B$ is the set of bidders that enter the auction and their valuations are given by $\left(v_{i}\right)_{i \in B}$. Once that announcement is made, the $N$ potential bidders simultaneously make their entry decisions. We focus on pure-strategy equilibria of the entry game. Those bidders who have entered learn their valuations and take part in the announced direct mechanism that corresponds to the actual set of entrants.

Bidder $i$ 's expected utility when she belongs to $B$, her valuation is $v_{i}$, and she decides to enter the auction expecting that all the other members of $B$ will enter as well, is

$$
U_{i}\left(v_{i}, B\right)=h_{i}\left(v_{i}, B\right) v_{i}-p_{i}\left(v_{i}, B\right)
$$

where $h_{i}\left(v_{i}, B\right)=E_{v_{-i}}\left[H_{i}^{B}\left(\left(v_{j}\right)_{j \in B}\right)\right]$ and $p_{i}\left(v_{i}, B\right)=E_{v_{-i}}\left[H_{i}^{B}\left(\left(v_{j}\right)_{j \in B}\right)\right], i \in B$.

The mechanism announced by the seller has to satisfy the corresponding incentive compatibility

$$
U_{i}\left(v_{i}, B\right) \geq h_{i}\left(v_{i}^{\prime}, B\right) v_{i}-p_{i}\left(v_{i}^{\prime}, B\right) \quad \text { for all } B \text {, for all } i \in B \text {, for all } v_{i}, v_{i}^{\prime}
$$

\footnotetext{
${ }^{5}$ Our results generalize to the case where the seller attaches a weight lower than one to the preferred bidder's utility.

${ }^{6}$ See Myerson (1981) and Riley and Samuelson (1982).

${ }^{7} 2^{\{1, \ldots, N\}}$ is the power set of $\{1, \ldots, N\}$.
} 
and participation constraints ${ }^{8}$

$$
U_{i}\left(v_{i}, B\right) \geq 0 \quad \text { for all } B \text {, for all } i \in B \text {, for all } v_{i}
$$

Given the seller's announcement, the equilibrium set of bidders, $B^{*}$, will be such that

$$
\begin{gathered}
\int_{\underline{v}}^{\bar{v}} U_{i}\left(v_{i}, B^{*}\right) f\left(v_{i}\right) d v_{i} \geq k, \forall i \in B^{*} \\
\int_{\underline{v}}^{\bar{v}} U_{j}\left(v_{j}, B^{*} \cup j\right) f\left(v_{j}\right) d v_{j} \leq k, \forall j \notin B^{*}
\end{gathered}
$$

The seller's problem is then ${ }^{9}$

$$
\max _{\substack{H_{1}^{B}\left(v_{1}, \ldots, v_{n}\right), P_{1}^{B}\left(v_{1}, \ldots, v_{n}\right) \\ B \in 2^{\{1, \ldots, N\}}}} \sum_{i \in B^{*}} \int_{\underline{v}}^{\bar{v}} p_{i}\left(v_{i}, B^{*}\right) f\left(v_{i}\right) d v_{i}+\int_{\underline{v}}^{\bar{v}} U_{1}\left(v_{1}, B^{*}\right) f\left(v_{1}\right) d v_{1}-k
$$

subject to (1), (2) and (3).

If the set of bidders, $B^{*}$, were exogenously fixed, following the usual steps in the auction literature, the seller's objective function becomes

$$
\int_{\underline{v}}^{\bar{v}} h_{1}\left(v_{1}\right) v_{1} f\left(v_{1}\right) d v_{1}+\sum_{\substack{i \in B^{*} \\ i \neq 1}} \int_{\underline{v}}^{\bar{v}} h_{i}\left(v_{i}\right) J\left(v_{i}\right) f\left(v_{i}\right) d v_{i}
$$

where $J(v)=v-\frac{1-F(v)}{f(v)}$. The allocation that solves this problem is well known ${ }^{10}$

$$
\begin{gathered}
H_{1}^{B^{*}}\left(\left(v_{j}\right)_{j \in B^{*}}\right)=\left\{\begin{array}{cc}
1 & \text { if } v_{1}>\max _{i \neq 1} J\left(v_{j}\right) \\
0 & \text { otherwise }
\end{array}\right. \\
H_{i}^{B^{*}}\left(\left(v_{j}\right)_{j \in B^{*}}\right)=\left\{\begin{array}{cc}
1 & \text { if } J\left(v_{i}\right)>\max \left\{v_{1}, \max _{j \neq i} J\left(v_{j}\right)\right\} \\
0 & \text { otherwise }
\end{array}\right.
\end{gathered}
$$

for $i \neq 1$. This is a discriminatory rule. However, when there is free entry of bidders the result substantially changes. The allocation rule, as we show in the following proposition, is a nondiscriminatory one.

Proposition 1 The allocation rule that maximizes joint expected surplus is a non discriminatory one. A first price or a second price auction that treats equally the favored and the non favored bidders maximizes joint surplus.

\footnotetext{
${ }^{8}$ Even after having paid the entry cost $k$, once she knows her valuation a bidder may choose not to take part in the selling mechanism.

${ }^{9}$ We are implicetly assuming that bidder 1 always enters. If this were not the case, the second and third terms in the objective function would disappear.

${ }^{10}$ See for example Arozamena and Weinschelbaum (2006).
} 
Proof. The expected value of the game (i.e. the expected total surplus in the auction) is the winning bidder's expected valuation minus the entry cost paid by entering bidders: $E v-\#\left(B^{*}\right) k .^{11}$ This, in turn, has to equal the expected revenue of the seller plus the summation of the surpluses of each of the bidders. As shown in McAfee and McMillan (1987), the allocation rule that maximizes expected total surplus by generating optimal entry awards the object to the entrant with the maximum valuation. If we ignore that the number of entrants has to be an integer, a first price or a second price auction with a reservation price equal to the seller's valuation maximizes the expected value of the game, and the seller receives the whole surplus. Considering the integer constraint, as McAfee and McMillan (1987) show, the seller can still maximize the value of the game and receive the whole surplus by charging an entry fee exactly equal to each entrant's expected utility when the number of entrants is the largest integer lower than the optimal number of entrants in a continuum. ${ }^{12}$

It just remains to prove that when the seller cares about bidder 1's surplus she cannot do better. If she could, she would be getting more than the maximal value of $E v-\#\left(B^{*}\right) k$. Thus, at least one of the bidders has to receive a negative expected surplus, which is clearly impossible

Note that the seller does not care if the favored bidder is in the set of entrants or not. This is because the expected surplus of each of the bidders is zero. The seller can give a subsidy to the preferred bidder to induce him to enter, but she would still get the same utility. But whenever the bidders that have entered are treated differently in the bidding process an inefficiency is created, and the seller's utility decreases.

The result holds for any number of preferred bidders whenever their surplus enters in the seller's utility function with a weight less than or equal to one. More generally it holds for any equilibrium in which the value of the game is maximized and the seller receives the whole surplus.

The result applies as well if we consider the symmetric, mixed-strategy equilibrium of the entry game studied in Levin and Smith (1994), since in that case the seller still receives the whole surplus. However, symmetric, mixed-strategy equilibria of the entry game are inefficient. The seller has incentives to induce some bidders to enter and move from the symmetric equilibrium

\footnotetext{
${ }^{11} \#\left(B^{*}\right)$ denotes the cardinality of the set $B^{*}$.

${ }^{12}$ Actually, as pointed out in Engelbrecht-Wiggans (1993), the seller may choose to subsidize entry so that the number of bidders is the lowest integer larger than the optimal number in a continuum. This way, she would still receive the whole surplus.
} 
to an asymmetric, pure-strategy, efficient one. These incentives are already present in Levin and Smith (1994). It doesn't matter if she subsidizes the preferred bidder or not: the seller is indifferent among any of the possible ways of moving from the symmetric equilibrium to the asymmetric one studied in McAfee and McMillan (1987).

Finally, as a corollary, note that whenever the seller gives a right of first refusal, if it matters, she awards the right-holder some advantage in the bidding process. This advantage generates an inefficiency. Thus, the seller's utility is reduced.

\section{References}

[1] Arozamena, L. and F. Weinschelbaum, "A Note on the Suboptimality of Right-of-FirstRefusal Clauses," Economics Bulletin, 4, No.24, 1-5, 2006.

[2] Bikhchandani, S., S. Lippman and R. Ryan, "On the Right-of-First-Refusal," Advances in Theoretical Economics, 1, No.1, Article 4, 2005.

[3] Branco, F., "Favoring Domestic Firms in Procurement Contracts," Journal of International Economics, 37, 65-80, 1994.

[4] Burguet, R. and M. Perry, "Preferred Suppliers in Auction Markets," RAND Journal of Economics, 40, 283-295, 2009.

[5] Celik, G. and O. Yilankaya, , Optimal Auctions with Simultaneous and Costly Participation," The B.E. Journal of Theoretical Economics, 9, Iss. 1 (Advances), Article 24, 2009.

[6] Choi, A., "A Rent Extraction Theory of Right of First Refusal," Journal of Industrial Economics, 57 Iss. 2, Pages 252 - 262, 2009.

[7] Engelbrecht-Wiggans R., "Optimal Reservation Prices in Auctions," Management Science, 33, 763-770, 1987.

[8] Engelbrecht-Wiggans R., "Optimal Auction Revisited," Games and Economic Behavior, 5, 227-239, 1993.

[9] Klemperer, P. "Auctions: Theory and Practice" Princeton University Press, 2004. 
[10] Laffont, J. and J. Tirole, "Auction Design and Favoritism," International Journal of Industrial Organization, 9, 9-42, 1991.

[11] Lee, J., "Favoritism in Asymmetric Procurement Auctions," International Journal of Industrial Organization, 26, 1407-1424, 2008.

[12] Levin, D. and J.L. Smith (1994) "Equilibrium in Auctions with Entry," American Economic Review, 84, No 3, 585-599, 1994.

[13] Li, T. and X. Zheng, "Entry and Competition Effects in First-Price Auctions: Theory and Evidence from Procurement Auctions," Review of Economic Studies, 76, 1397-1429, 2009.

[14] McAfee, R.P. and J. McMillan, "Auctions with Entry," Economics Letters, 23, 343-347, 1987.

[15] McAfee, R.P. and J. McMillan, "Government Procurement and International Trade," Journal of International Economics, 26, 291-308, 1989.

[16] Menezes, F. M. and P. K. Monteiro, "Auctions with Endogenous Participation," Review of Economic Design 5, 71-89, 2000.

[17] Myerson, R. (1981) "Optimal Auction Design" Mathematics of Operations Research, 6, 58-73.

[18] Naegelen, F. and M. Mougeot, "Discriminatory Public Procurement Policy and Cost Reduction Incentives," Journal of Public Economics, 67, 349-367, 1998.

[19] Riley, J. and W. Samuelson (1982) "Optimal Auctions" American Economic Review, 71, 381-392.

[20] Samuelson, W. F., "Competitive Bidding with Entry Costs," Economics Letters 17, 53-57, 1985.

[21] Stegeman, M., "Participation Costs and Efficient Auctions," Journal of Economic Theory 71, 228-259, 1996.

[22] Vagstad, S., "Promoting Fair Competition in Public Procurement," Journal of Public Economics, 58, 283-307, 1995. 
[23] Walker, D. (1999) "Rethinking Rights of First Refusal" Stanford Journal of Law, Business and Finance, 5, 1-58.

[24] Ye L., "Optimal auctions with endogenous entry", Contributions to Theoretical Economics, 4, article 8, 2004. 